\title{
Laboratório de Física IV baseado em experimentos de baixo custo: relato de uma experiência de ensino remoto devido à pandemia de COVID-19
}

\author{
Laboratory Physics IV based on low-cost experiments: a report on a remote teaching experience
} due to the COVID-19 pandemic

\author{
Giovana Trevisan Nogueira*1@ Júlio Akashi Hernandes ${ }^{1}[$ \\ ${ }^{1}$ Universidade Federal de Juiz de Fora, Juiz de Fora, MG, Brasil
}

Recebido em 02 de julho de 2021. Revisado em 23 de agosto de 2021. Aceito em 26 de agosto de 2021.

\begin{abstract}
Neste trabalho, apresentamos um relato do oferecimento da disciplina de Laboratório de Física IV em regime de ensino remoto emergencial por causa da pandemia de Covid-19. Nesta disciplina, que faz parte da grade de cursos superiores das áreas de Ciências Exatas e Engenharias, experimentos elaborados com materiais de baixo custo e de fácil acesso foram realizados pelos alunos nas suas próprias casas, com suporte do professor por meio de aulas síncronas (por web-conferência), e-mails e fóruns de discussão. As atividades experimentais foram elaboradas principalmente a partir de artigos de revistas de Ensino de Física e envolvem temas de óptica geométrica, óptica física, interferômetro de Michelson e espectroscopia. Apresentamos, aqui, a descrição desses experimentos, bem como resultados obtidos por alunos em cada uma das atividades. Mostramos que os alunos foram capazes de implementar as montagens experimentais e de realizar as medidas quantitativas com cuidado e precisão semelhantes aos que seriam feitos em experimentos presenciais equivalentes dos laboratórios de ensino das universidades.
\end{abstract}

Palavras chave: Ensino Remoto, Ensino à distância, Experimentos de baixo custo, Óptica, Covid-19.

In this work, we present a report on the offer of the discipline of Physics Laboratory IV discipline in a emergency remote learning regime because of the Covid-19 pandemic. In this discipline, which is part of the curriculum of higher education courses in the Exact Sciences area and Engineering, experiments designed with low-cost and accessible materials were carried out by students in their own homes, with teacher support through synchronous classes (via web-conference), e-mail and discussion forums. The experimental activities were elaborated mainly from articles published in Physics Education journals and involve themes of geometric optics, physical optics, Michelson interferometer and spectroscopy. We present here the description of these experiments as well as the results obtained by students in each one of them. We show that the students were able to permorm the experimental setups, as well as the quantitative measurements with care and precision similar to what would be carried out in equivalent face-to-face experiments at physics teaching laboratories.

Keywords: Remote Learning, Distance Learning, Low Cost Experiments, Optics, Covid-19.

\section{Introdução}

A pandemia de COVID-19 trouxe novos desafios para o ensino superior experimental. Disciplinas usualmente realizadas em laboratórios com espaços fechados, em grupo e que exigem manipulação e compartilhamento de materiais por vários alunos foram suspensas ou tiveram que ser remodeladas. Dentro deste contexto, apresentamos aqui uma abordagem utilizada para o oferecimento da disciplina de Laboratório de Física IV (óptica e física moderna) da grade curricular de cursos das áreas de Ciências Exatas e Engenharias da Universidade Federal de Juiz de Fora (UFJF). Essa abordagem é baseada em experimentos com materiais de baixo custo, realizados

\footnotetext{
* Endereço de correspondência: giovana@ice.ufjf.br
}

pelos alunos em casa, com apoio do professor por meios remotos (web-conferencia, e-mails, fóruns, etc.).

O desenvolvimento desta implementação alternativa para o ensino emergencial teve como inspiração uma experiência anterior na disciplina de Laboratório de Física IV do curso de Licenciatura em Física à Distância (EAD) também realizada de modo emergencial em 2018. Naquela ocasião, a greve dos caminhoneiros ocorrida em maio [1] impossibilitou que os alunos realizassem os experimentos referentes à última metade da disciplina, usualmente realizada presencialmente nos laboratórios da universidade.

$\mathrm{O}$ relato descrito aqui corresponde ao oferecimento para duas turmas do ensino presencial em caráter remoto emergencial (ERE), referentes ao primeiro e ao segundo semestres de 2020, e para as turmas do ensino à distância 
(EAD) referentes ao primeiro semestre de 2018 e ao segundo semestre de 2020.

Fazemos aqui a distinção de Ensino à Distância (EAD) de Ensino Remoto Emergencial (ERE). No primeiro caso, estamos falando do curso regular à distância, dentro do projeto Universidade Aberta do Brasil (UAB). ERE refere-se ao ensino de disciplinas de cursos presenciais mas realizadas de forma remota devido à pandemia de COVID-19. Utilizamos aqui a notação de 2020.1 para o primeiro semestre do ano letivo de 2020 e 2020.2 para o segundo semestre letivo do ano 2020.

\section{A experimentação com materiais de baixo custo}

O uso de materiais de baixo custo para a realização de experimentos já é uma realidade em oficinas de ensino de Física, laboratórios em espaços não formais e até mesmo em sala de aula do ensino médio e fundamental [2 4]. Os defensores deste tipo de abordagem descrevem que a experimentação utilizando materiais de baixo custo dá ao professor liberdade para realizar experimentos sem a dependência de infraestrutura e de equipamentos usualmente indisponíveis em escolas públicas. Além do custo, alguns autores também apontam que o uso de materiais de baixo custo permite que o aluno construa seu próprio experimento e se aproxime do fenômeno físico 2 .

No Ensino superior, devido à disponibilidade de laboratórios estruturados na maioria das universidades públicas e privadas, experimentos com materiais de baixo custo raramente são realizados em disciplinas de laboratórios básicos obrigatórios. As metodologias de ensino normalmente seguem o modelo de laboratório tradicional [5], no qual os equipamentos utilizados nos experimentos são oferecidos prontos e aos alunos cabe a tarefa de seguir procedimentos em geral rígidos e prédefinidos pelo professor.

O uso de materiais de baixo custo associados a metodologias de ensino investigativas [5, 6] e [7 podem enriquecer as disciplinas de cursos superiores, mesmo aquelas que possuem laboratórios bem equipados, no sentido de que o aluno deixa de ter uma atuação passiva, em que recebe o equipamento pronto e passa a ter uma atuação ativa, precisando também planejar e desenvolver seu próprio equipamento de medida.

Adaptações de trabalhos originalmente pensados para o ensino médio podem ser feitas para o ensino superior. Um dos experimentos descrito neste trabalho, por exemplo, é uma adaptação para a disciplina de Laboratório de Física IV do trabalho descrito por T. A. Ricardo, em sua dissertação de mestrado [8], na qual apresenta a construção de um espectrômetro de baixo custo e o desenvolvimento de projetos por alunos de ensino médio para estudar a influência da composição espectral de diferentes tipos de lâmpadas de filmes na iluminação ambiente, bem como a alteração que filmes e películas em vidros de janelas provocam na iluminação natural de uma casa.

Também utilizamos como base da elaboração desta disciplina artigos de ensino descrevendo a construção de um interferômetro de Michelson com materiais de baixo custo [9, 10] e experimentos de óptica geométrica [11, 12] e de difração da luz [13.

Nas adaptações para uma disciplina de curso superior realizadas aqui, além de inserir um grau de profundidade maior no estudo dos fenômenos, também acrescentamos elementos de medidas quantitativas e análises estatísticas de dados, que são usuais nos laboratórios básicos de cursos da área de Ciências Exatas e Engenharias.

\section{O histórico de desenvolvimento desta abordagem}

Experimentos com materiais de baixo custo foram utilizados na disciplina de Laboratório de Física IV, primeiramente e de forma emergencial, em uma turma do curso de Licenciatura em Física EAD da UFJF em 2018. O Curso de Licenciatura em Física à Distância (LFEAD) da UFJF foi criado em 2008, dentro do programa Universidade Aberta do Brasil (UAB). Ele foi baseado, inicialmente, na metodologia proposta pelo Consórcio CEDER. 1 . cidades-polo, e disciplinas semi-presenciais semestrais: as aulas teóricas eram realizadas por computador, através da plataforma Moodle, e aulas experimentais e avaliações presenciais seriam realizadas nos polos, mantidos pelas prefeituras das cidades-polo. Entretanto, houve dificuldade na criação da infraestrutura para a realização das disciplinas experimentais nos polos. A maioria das prefeituras das cidades cadastradas como polos nunca entregou os Laboratórios de Física I à IV. Por isso, a partir de 2010 a coordenação do curso optou por organizar viagens dos alunos da cidade-polo até Juiz de Fora, para realizar as atividades experimentais nos laboratórios de ensino de Física da UFJF. Estas viagens eram realizadas duas vezes por semestre letivo, em finais de semana. Nas demais semanas, as atividades experimentais dos alunos eram complementadas por simulações e vídeos, análise dos dados, produção de relatórios, e avaliações.

O uso de materiais de baixo custo na disciplina de Laboratório de Física IV tornou-se necessário no ano de 2018, em virtude dos problemas de locomoção causados pela greve dos caminhoneiros iniciada em 21 de maio de 2018 e que teve duração de 10 dias. Este período envolveu a data da segunda viagem do semestre para a realização dos experimentos. Diante dessa situação, em caráter experimental, optou-se pela realização de três experimentos pelos alunos em casa com materiais de baixo custo, a partir de artigos publicados em revistas

\footnotetext{
1 Centro de Ciências e Educação Superior à Distância do Estado do Rio de Janeiro.
} 
de ensino: medida da espessura de um fio de cabelo por difração da luz [13], montagem de um espectrômetro de Michelson 9] e montagem de um espectrômetro de baixo custo [14.

Naquela ocasião, não foram elaborados roteiros rígidos para os experimentos. Ao contrário, foram passados os artigos de revistas de ensino de física para leitura, com a orientação de que eles teriam que adaptar os experimentos descritos nos artigos aos materiais que eles tivessem acesso em casa ou nos polos, com suporte do professor. Eles deveriam filmar os experimentos e elaborar um relatório descrevendo a montagem e os resultados obtidos. Os alunos também foram orientados a encaminhar um vídeo intermediário, para acompanhamento pelo professor, da evolução dos experimentos. Eles tiveram 30 dias para encaminhar os relatórios. Os trabalhos encaminhados pelos alunos foram bons o suficiente para que esta dinâmica fosse utilizada novamente em uma nova oferta da disciplina em 2019, com a adição de um quarto experimento com a temática de óptica geométrica 12 .

Com a chegada da pandemia de COVID-19 em 2020 ao Brasil, as aulas presenciais da UFJF foram suspensas para adaptação das atividades da universidade ao ensino remoto. As disciplinas EAD continuaram normalmente, ou seja, os semestres 2020.1 e 2020.2 EAD duraram 15 semanas, de março a julho de 2020 e de agosto a dezembro de 2020, respectivamente. Os semestres 2020.1 e 2020.2 dos cursos presenciais ERE duraram 10 semanas, de setembro a novembro de 2020 e de dezembro de 2020 a fevereiro de 2021, respectivamente, utilizando as plataformas Moodle, Google Classroom e Google Meet para aulas remotas.

Dentro da UFJF, a maioria dos departamentos decidiu suspender o oferecimento de disciplinas experimentais. No Departamento de Física, entretanto, um grupo de professores desenvolveu propostas para implementar disciplinas experimentais utilizando vídeos, simuladores e experimentos de baixo custo para manter o oferecimento destas disciplinas.

Nas próximas seções, iremos apresentar a adaptação da disciplina de Laboratório de Física IV para os regimes ERE e EAD de 2020, a partir da experiência anterior da disciplina de Laboratório de Física IV EAD de 2018. Esta disciplina foi oferecida dentro desta proposta para turmas EAD de 2018.1 e de 2020.2, com 11 e 12 alunos matriculados, respectivamente, e para as turmas no regime ERE dos semestres 2020.1 e 2020.2, com 11 e 13 alunos matriculados, respectivamente.

\section{A proposta para o Ensino Remoto Emergencial}

A disciplina de Laboratório de Física IV é uma disciplina experimental relacionada aos conceitos de produção e propagação de ondas eletromagnéticas e óptica. No formato ERE, ela foi composta por dois tipos de atividades: tarefas sobre geração e propagação de ondas eletromagnéticas utilizando simuladores on-line e experimentos de óptica utilizando materiais de baixo custo que foram montados e realizados em casa. As atividades experimentais foram intercaladas com atividades em simuladores para não sobrecarregar os alunos, uma vez que as atividades com materiais de baixo custo exigem, além da execução do experimento, a busca de materiais, o planejamento do experimento e a montagem do sistema em que o experimento será realizado.

Esta disciplina foi ministrada, majoritariamente, em modo assíncrono. Uma vez por semana, às segundasfeiras, foram disponibilizadas na plataforma Google Classroom, instruções de tarefas ou experimentos para os alunos realizarem com prazos de uma ou duas semanas, dependendo do experimento. Os alunos tiveram suporte do professor através da plataforma Google Classroom, por e-mail e por meio de aulas síncronas (por webconferência) realizadas às sextas-feiras, no que seria o horário regular das aulas presenciais. Em alguns casos, também foram disponibilizados vídeos explicativos elaborados pelo professor regente da turma, com comentários sobre dúvidas e pontos mais complexos na execução dos experimentos, ou demonstrações de como construir o sistema experimental. Para auxiliar aqueles que desejarem reproduzir os experimentos apresentados aqui, deixamos na Tabela 1, um resumo destes, indicando o material e as principais referências utilizados na elaboração das instruções apresentadas aos alunos.

\section{Resultados}

Nesta seção, discutimos como foi a implementação dos experimentos de baixo custo citados na Tabela 1 mostrando alguns resultados encontrados pelos alunos e apontando suas dificuldades na realização dos experimentos. Damos uma maior ênfase aos experimentos do interferômetro de Michelson de espectroscopia por serem os mais complexos em termos de execução e análise dos resultados pelos alunos. Os simuladores utilizados pertencem ao projeto PhET Simulações Interativas da Universidade do Colorado (EUA) ${ }^{2}$ de uso gratuito. Não entraremos em detalhes sobre a utilização dos simuladores porque são mais simples de serem adaptados às aulas on-line. Os nomes dos alunos são fictícios. As turmas específicas serão citadas apenas quando esta informação for relevante para a discussão. Os gráficos elaborados pelos estudantes são apresentados conforme foram entregues nos relatórios, inclusive com eventuais erros, tendo sido feita edição apenas para escurecer e ampliar as fontes, para uma melhor visualização neste trabalho.

${ }_{2}^{2}$ Acesso por: https://phet.colorado.edu/pt_BR/ 
Tabela 1: Síntese dos experimentos realizados na disciplina de Laboratório de Física IV/UFJF durante o Ensino Remoto Emergencial de 2020 .

\begin{tabular}{|c|c|c|}
\hline Experimento & Material utilizado & Referências \\
\hline $\begin{array}{l}\text { Estudo da iluminação ambiente de um } \\
\text { dos cômodo da casa }\end{array}$ & Celular com luxímetro instalado & [15] 17 \\
\hline Experimento de óptica geométrica & $\begin{array}{l}\text { Lupa, régua, caneta laser (laser pointer), garrafa PET, } \\
\text { saquinho de salgadinho metalizado }\end{array}$ & $11,12,18$ \\
\hline $\begin{array}{l}\text { Difração de luz monocromática: medida } \\
\text { da espessura de um fio de cabelo }\end{array}$ & $\begin{array}{l}\text { Caneta laser, um fio de cabelo, régua e/ou papel } \\
\text { milimetrado, fita adesiva }\end{array}$ & 13 \\
\hline Interferômetro de Michelson & $\begin{array}{l}\text { Espelhos pequenos, massinha de modelar, suportes para os } \\
\text { espelhos pequenos (potes plásticos, pedaços de madeira, } \\
\text { etc,), um pedaço de plástico ou vidro plano e limpo, lupa }\end{array}$ & [9, 10] \\
\hline $\begin{array}{l}\text { Espectroscopia (montagem de um } \\
\text { espectrômetro de baixo custo e } \\
\text { caracterização espectral de diferentes } \\
\text { fontes luminosas) }\end{array}$ & $\begin{array}{l}\text { Papelão, CD velho, diversas fontes luminosas (vela, } \\
\text { lâmpadas de vários tipos, etc...), programa simples de } \\
\text { edição de imagem }\end{array}$ & [8, 14 \\
\hline
\end{tabular}

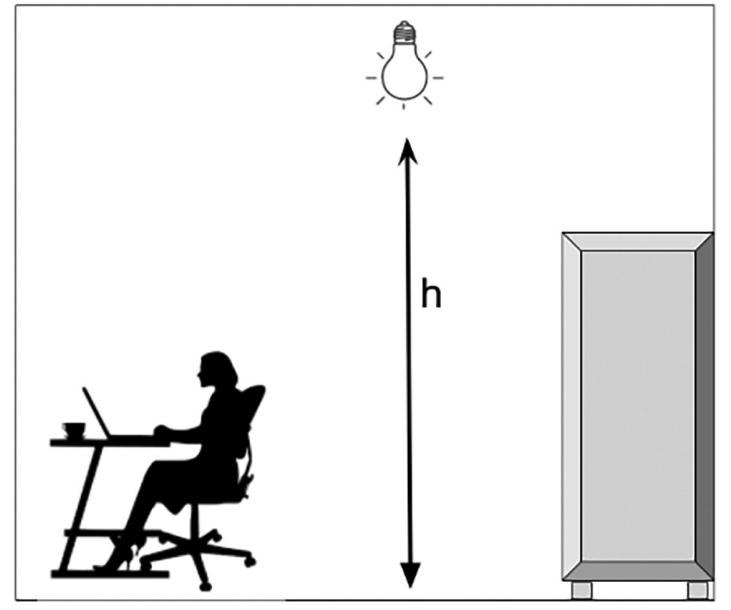

Figura 1: Esquema da medida da intensidade da luz em função da distância apresentado aos alunos. Fonte: Acervo pessoal dos autores.

\subsection{Estudo da iluminação ambiente de um cômodo da casa}

O primeiro experimento apresentado aos alunos foi sobre medida da intensidade luminosa em um dos cômodos da casa do próprio aluno (de livre escolha) e a adequação desta iluminação às atividades realizadas neste cômodo segundo a Norma Técnica ABNT NBR 54113 [16] [17]. Foram solicitadas aos alunos a medida do decaimento da intensidade luminosa com a distância da lâmpada a partir de uma linha vertical abaixo da lâmpada (Fig. 1), a medida da iluminação média da luz do ambiente, de acordo com a metodologia mostrada em [15] e a medida do fluxo luminoso em um ponto específico do cômodo em questão (p. ex. na mesa de estudo, onde o aluno costuma ler, etc.). Os dados da iluminação média e puntual foram então comparados com a Norma Técnica ABNT NBR 54113 para verificar se a iluminação está adequada para a atividade desenvolvida no ambiente. Para a realização da tarefa, os alunos utilizaram seus celulares com um aplicativo luxímetro instalado.
Há vários pontos importantes para ressaltar neste experimento. O primeiro é a inserção de uma contextualização do experimento. $\mathrm{O}$ objetivo principal deste experimento era estudar o decaimento da intensidade da luz de fontes puntuais com o quadrado da distância. A inserção de estudos de adequação luminosa foi feita para inserir um fator motivacional no experimento. Embora "elemento de motivação" seja algo subjetivo, foi perceptível, durante as trocas de mensagem e na participação da aula síncrona de dúvidas, o interesse e curiosidade dos alunos em realizar a caracterização do ambiente de sua própria casa. O segundo ponto a ser ressaltado está relacionado aos tipos de medidas realizadas em casa. Apesar de ser um experimento de execução simples, os alunos precisaram executar e interpretar uma medida que resultou em um gráfico, uma medida envolvendo valor médio de uma grandeza física medido em vários pontos de uma área e a medida de um valor em um local específico de interesse. O terceiro ponto a ser ressaltado é que este experimento não menciona detalhes sobre como as medidas seriam realizadas e os alunos tiveram que elaborar suas próprias metodologias de medidas. Por exemplo, para medir a intensidade da luz em função da distância da lâmpada, alguns alunos usaram escadas para mudar a altura do celular, outros empilharam livros, outros usaram tripés de filmadoras. Apesar disso, observamos que as medidas obtidas pelos alunos possuem precisão equivalente à que seria obtida nos laboratórios de ensino de universidade.

O gráfico da Figura 2 elaborado pelo aluno Lucas, é um exemplo de um resultado típico apresentado pelos alunos em relatório. O ajuste da curva foi feito para uma curva experimental, do tipo $I=I_{o} h^{r}$, onde $I_{o}$ e $r$ são as variáveis desconhecidas. Este ajuste foi realizado para comparar com o espalhamento da luz no caso de uma fonte puntual, onde $\mathrm{r}=-2$. É nítido pelo gráfico da Figura 2 que o valor de $r=-1,86$ difere de -2 , muito provavelmente, pela lâmpada não ser pontual e não por problemas na medida em si.

O único fator limitador deste experimento é que nem todos os alunos possuem celular com um sensor de 
Intensidade (Lux) vs. Distância (Metro)

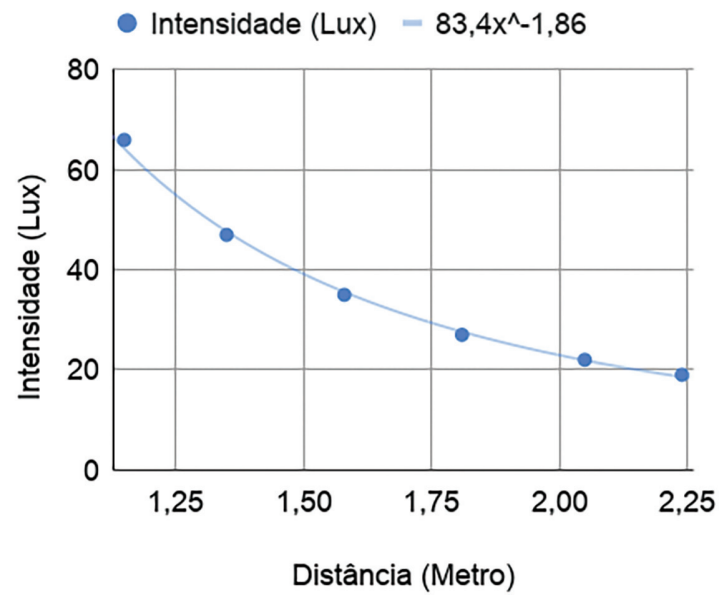

Figura 2: Gráfico da Intensidade da Luz em função da distância construído por um dos alunos do ensino ERE de 2020. A linha azul é o ajuste de uma curva utilizando uma planilha eletrônica, correspondente à equação apresentada acima do gráfico.

luminosidade. Nas três turmas nas quais este roteiro foi apresentado (ERE 2020.1 e 2020.2 e EAD 2020.2), apenas 3 alunos de um total de 36 não conseguiram realizar o experimento por este motivo. Nestes casos, os alunos realizaram o experimento de óptica geométrica.

\subsection{Experimento de óptica geométrica}

O experimento de óptica geométrica foi utilizado por todos os alunos apenas na turma EAD 2020.2, que teve um semestre de 15 semanas. Para as turmas ERE, com semestres de 10 semanas, ele foi utilizado como substituto do experimento sobre intensidade luminosa pelos alunos que não possuíam um celular com o luxímetro instalado. Este experimento baseou-se no trabalho de Viscovini [12] e consistiu em utilizar uma caneta laser para realizar medidas da distância focal de uma lupa, traçar os raios de incidência e reflexão em um espelho plano, determinar o foco de um espelho curvo e medir o índice de refração de um meio transparente. O espelho curvo foi construído a partir de garrafa PET [18] e embalagem de alimentos espelhada, como mostra a Figura 3

As medidas com os espelhos e as lentes foram realizadas por todos os alunos sem grandes dificuldades. A Figura 4 mostra duas observações distintas realizadas por dois alunos para a medida da distância focal do espelho curvo. Observa-se que cada aluno encontrou uma maneira distinta para a realização das medidas. Embora estes sejam experimentos simples, eles são de grande importância, principalmente para os cursos de licenciatura, pois podem ser levados para sala de aula de ensino médio posteriormente.

A Figura 5 mostra duas implementações para a medida do índice de refração da água. Novamente, podemos observar a criatividade de cada aluno para encontrar
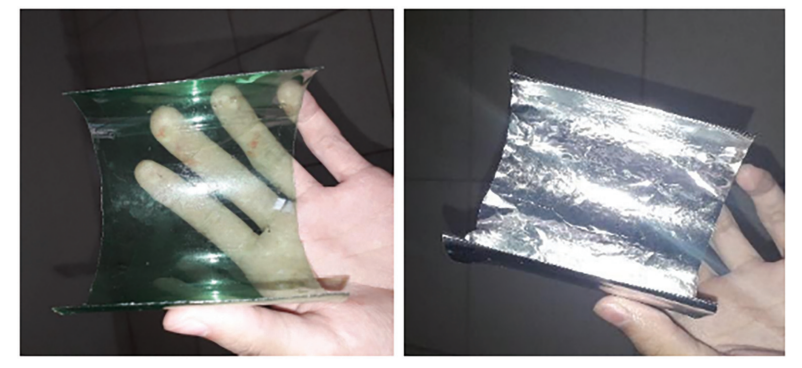

Figura 3: Material utilizado para a construção do espelho curvo: à esquerda, um pedaço de garrafa PET cortado em um formato de semi-cilindro. À direita, o mesmo pedaço de garrafa, laminado com uma folha de embalagem de salgadinho, para formar um espelho côncavo.
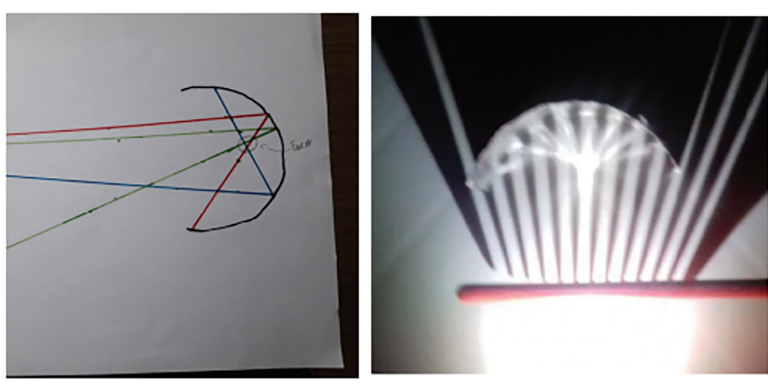

Figura 4: Resultados da medida do foco do espelho côncavo apresentados nos relatórios de dois alunos. À esquerda, o aluno utilizou a caneta laser para observar e traçar em um papel os feixes incidentes e os respectivos feixes refletidos. Na imagem à direita, o aluno utilizou uma lanterna associada a um pente para criar vários raios luminosos incidindo no espelho curvo, e, com isso, observar a convergência dos feixes refletidos no foco.
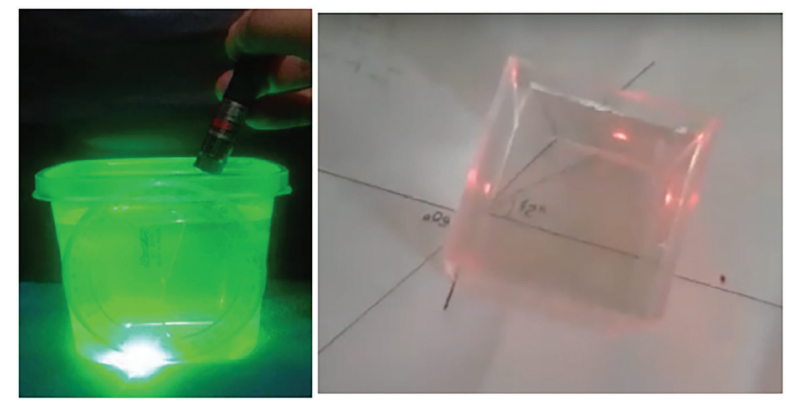

Figura 5: Montagens realizadas por dois alunos para a observação da Lei de Snell na interface ar-água. Na Figura à esquerda, o aluno Francisco colocou um transferidor dentro de um recipiente com água, para medir o ângulo dos feixes incidente e refratado de uma caneta laser. Na Figura à direita, - aluno Carlo utilizou um recipiente quadrado de plástico transparente com água dentro colocado sobre um papel. Os feixes de incidência e de refração foram registrados com marcas no papel.

adaptações do material de casa para realizar a medida solicitada. No primeiro caso, o aluno Francisco utilizou um transferidor dentro de um pote plástico ajustado no plano da vertical para realizar as medidas dos ângulos 


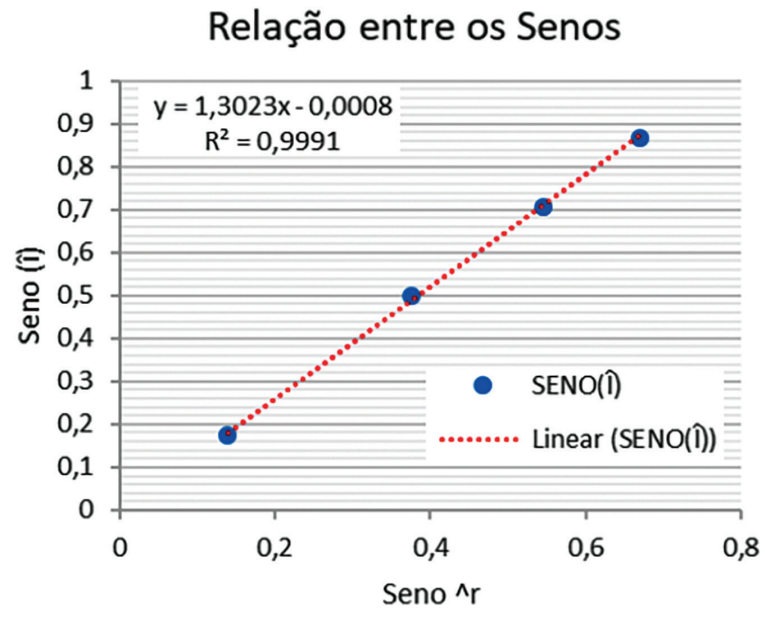

Figura 6: Gráfico apresentado no relatório pelo aluno Carlo, que realizou a montagem da Figura 5 à direita, do seno do ângulo de incidência em função do seno do ângulo de refração. A linha tracejada é a linearização dos pontos medidos, correspondente à equação apresentada no canto superior esquerdo da Figura.

de incidência e refração de um feixe laser. No segundo caso, o aluno Carlo realizou o experimento no plano horizontal, utilizando um recipiente plástico transparente quadrado para observar os ângulos de incidência e refração. Neste caso, o aluno marcou a trajetória do feixe incidente e do feixe refratado em um papel colocado embaixo do recipiente.

A Figura 6 mostra o gráfico do seno do ângulo de incidência em função do seno do ângulo de refração e o ajuste linear, obtido pelo aluno Carlo, resultando em um índice de refração igual a 1,30 e $R^{2}=0,9991$. Novamente, observamos medidas com um grau de precisão semelhante ao que os alunos apresentariam em um experimento equivalente realizado presencialmente no laboratório de ensino da universidade.

\subsection{Medida da espessura de um fio de cabelo}

O experimento para medir a espessura de um fio de cabelo é comumente realizado em disciplinas de Laboratórios de Física IV presenciais. Ele envolve o conceito de difração da luz em fendas ou obstáculos muito estreitos. No ensino EAD e ERE, foi solicitado aos alunos que executassem a montagem mostrada na Figura 7, utilizando uma caneta laser (vermelha ou verde) como fonte de luz e um fio de cabelo no lugar onde usualmente se colocam fendas. O padrão de difração é, então, observado em um anteparo atrás do fio de cabelo, oposto à fonte de luz.

Os alunos deveriam medir a distância $h_{m}$ entre o máximo central do padrão de interferência produzido e os mínimos de intensidade subjacentes para produzir um gráfico de $h_{m}$ em função de $m$. Aqui, $m=1,2,3 \ldots$ é a ordem do mínimo de difração correspondente à $h_{m}$. $\mathrm{O}$ valor da espessura do fio de cabelo e o seu erro experimental foram determinados utilizando-se o método

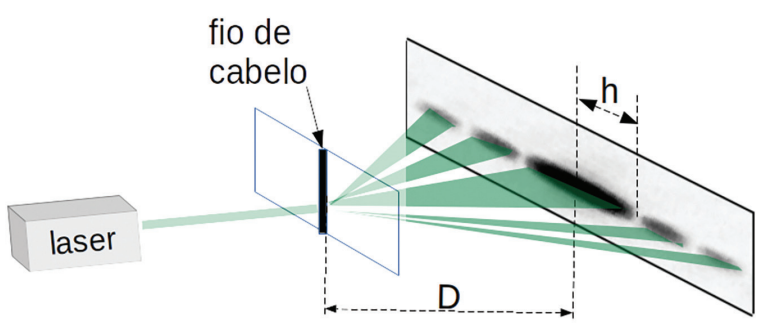

Figura 7: Esquema da montagem óptica para a medida da espessura de um fio de cabelo por difração de luz laser.

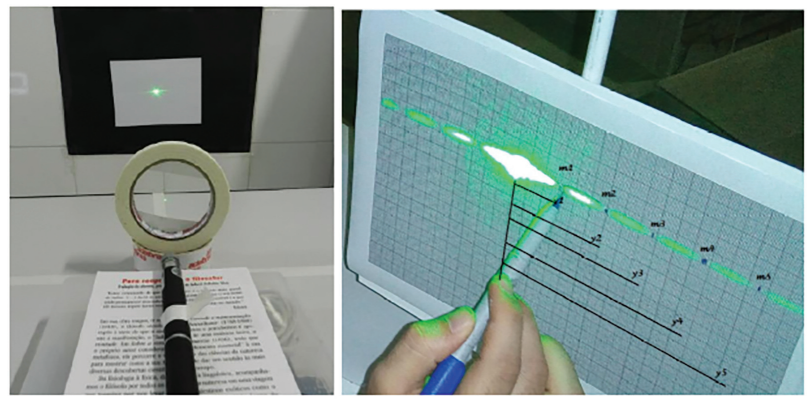

Figura 8: À esquerda: montagem realizada pelo aluno Diego para a medida da espessura de um fio de cabelo. À direita: medida de $h_{m}$ correspondente à cada mínimo de interferência, obtida pelo aluno Saulo.

dos quadrados mínimos para determinar o coeficiente angular do gráfico de $h_{m}$ em função de $m$.

A Figura 8 à esquerda, mostra uma montagem realizada pelo aluno Diego. Neste caso, o aluno usou um rolo de fita adesiva como suporte do fio de cabelo. Outros alunos utilizaram materiais como clipes, papelão e copos. A Figura 8 à direita, mostra a imagem do padrão de difração retirada do relatórios do aluno Saulo. Observase a realização da medida da distância $h_{m}$ para cada um dos mínimos $m$, utilizando-se um papel milimetrado. Outros alunos desenharam o padrão em uma folha e mediram os mínimos com uma régua. A realização deste experimento pelos alunos foi extremamente simples e não houve dificuldades para a sua realização em casa.

A Figura 9 mostra o gráfico de $h_{m}$ em função de $m$. obtido por Matheus. O ajuste de uma reta aos pontos obtidos resultou em $\mathrm{R}=0,999$, indicando bastante precisão na medida de $h_{m}$. A Figura 10 mostra um histograma dos valores encontrados para medida da espessura de um fio de cabelo pelos alunos das turmas EAD e ERE de 2020.1 e 2020.2. Observa-se que todos os alunos encontraram valores com a mesma ordem de grandeza, sendo um indicativo de que não houve dificuldade na execução deste experimento em casa. Esta compilação dos valores foi fornecida aos alunos para que eles pudessem comparar o resultado obtido individualmente com os valores obtidos pelos demais e interpretar a variação dos valores, tanto em termos de erros experimentais quanto pelo fato de que cada aluno utilizou um fio de cabelo diferente. 


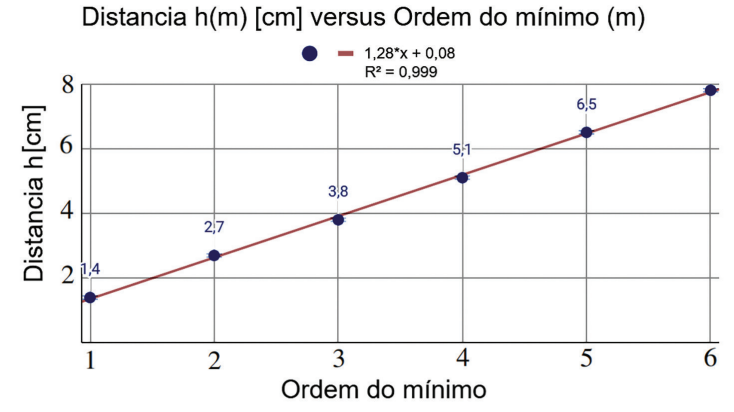

Figura 9: Gráfico de $h_{m}$ em função de $m$ obtido pelo aluno Matheus. $\mathrm{O}$ ajuste de uma reta aos pontos obtidos resultou em $h_{m}=1,28 m+0,08$, com $\mathrm{R}=0,999$.

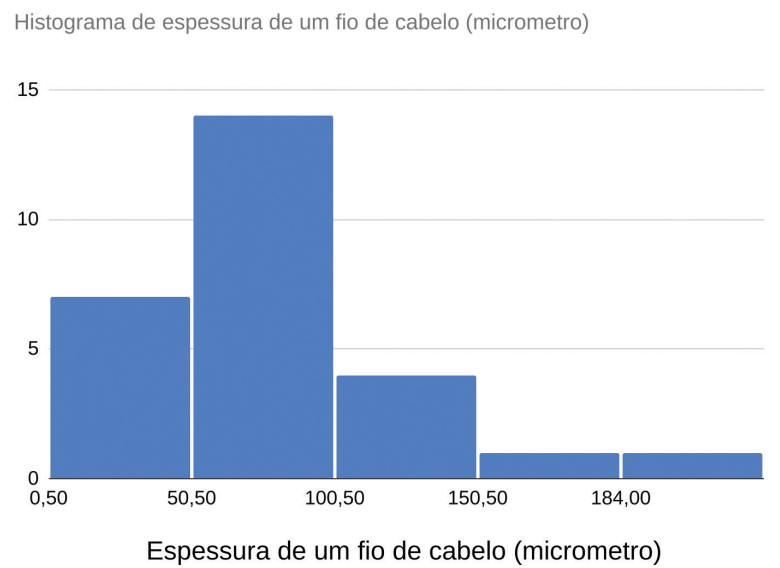

Figura 10: Histograma dos valores encontrados para medida da espessura de um fio de cabelo pelos alunos das turmas EAD e ERE de 2020.1 e 2020.2

\subsection{Construção de um interferômetro de Michelson caseiro}

O experimento do interferômetro de Michelson com materiais de baixo custo foi realizado baseando-se nos trabalhos de Catelli e Vicenzi [9] e de Silva, Giacomelli, Pérez e Silva [10]. Em atividades em laboratórios de ensino, o interferômetro de Michelson geralmente é utilizado para a medida do comprimento de onda de um laser ou do índice de refração de algum material. Na abordagem realizada pelos alunos do ERE e EAD descrita neste trabalho, este experimento teve um caráter apenas qualitativo. Este experimento não pôde ser trabalhado em casa com medidas quantitativas porque isso necessitaria de um sistema de deslocamento de um dos espelhos do interferômetro com precisão de micrômetros, algo indisponível aos alunos trabalhando em casa. Além disso, o interferômetro de Michelson é extremamente sensível a ruídos mecânicos vindos do chão ou mesmo do ar. Para a realização dessas medições, o interferômetro deve ser colocado em uma mesa apropriada com atenuação de ruído (uma mesa de granito espessa, ou sobre câmera de ar ou espuma grossa), e em ambiente livre de corrente de ar e barulho.
Entretanto, mesmo sendo um experimento apenas qualitativo e de difícil montagem, a realização deste experimento em casa foi mantida na disciplina pelos seguintes motivos: 1- importância histórica deste experimento; 2- apoio à disciplina de Física IV teórica, na qual este interferômetro é bastante estudado; 3- manipulação de elementos ópticos, como espelho, divisor de feixe e lente em um sistema diferente do que é usado em óptica geométrica; 4- a percepção da sensibilidade deste interferômetro em relação a ruídos e discussão de seu uso em laboratórios de pesquisa, como, por exemplo, no experimento de medida de ondas gravitacionais realizado em 2015 nos Estados Unidos [19]; 5- treinamento da montagem deste interferômetro para incentivar os alunos de licenciatura a levar este experimento às aulas de ensino médio posteriormente.

O experimento do interferômetro de Michelson foi o mais difícil de ser executado pelos alunos. Devido a esta complexidade, este experimento foi realizado ao longo de duas semanas. Os alunos tiveram que enviar um vídeo e fotografias em caráter preliminar no final da primeira semana para que o professor pudesse acompanhar o desenvolvimento do trabalho, ajudar a superar as dificuldades e apontar os problemas na montagem. Ao longo das duas semanas, os alunos também tiveram suporte por videoconferência e fórum de discussão.

Uma dificuldade bastante comum entre os alunos foi em reconhecer o padrão de interferência. Muitas vezes, como o interferômetro estava desalinhado, a projeção do laser em um anteparo apresentava manchas escuras devido à sujeira nos elementos ópticos ou à baixa qualidade do laser, que foram confundidas com o padrão de interferência. Outra dificuldade comum foi na utilização da lupa para ampliar o diâmetro do feixe de saída do interferômetro e facilitar a visualização do padrão de interferência: alguns alunos não conseguiram, em um primeiro momento, entender que o feixe deveria passar através da lupa. Estes alunos tentaram utilizar a lupa olhando a projeção do feixe através dela, como se faz para ler letras pequenas, por exemplo.

Outro ponto importante a ressaltar é que alguns alunos usaram um vidro grosso como divisor de feixe. As reflexões em cada uma das faces do vidro gerou dois feixes independentes na saída do interferômetro, conforme mostra a Figura 11, causando um pouco de confusão na hora do ajuste dos espelhos.

Para ajudar os alunos a sanar estas dúvidas, durante o período de execução do experimento na turma EAD 2018 foi produzido um primeiro víded ${ }^{3}$ de apoio mostrando o interferômetro de um laboratório da universidade. Neste vídeo, além de mostrar como se usa a lente adequadamente, foi explicado aos alunos que, para ter certeza de que é o padrão de interferência, eles deveriam bloquear um dos braços do interferômetro e verificar se o padrão de interferência some. Posteriormente, durante

${ }^{3}$ Acesso por: https://www.youtube.com/watch?v=faSHvVTrujE $\& \mathrm{t}=61 \mathrm{~s}$ 


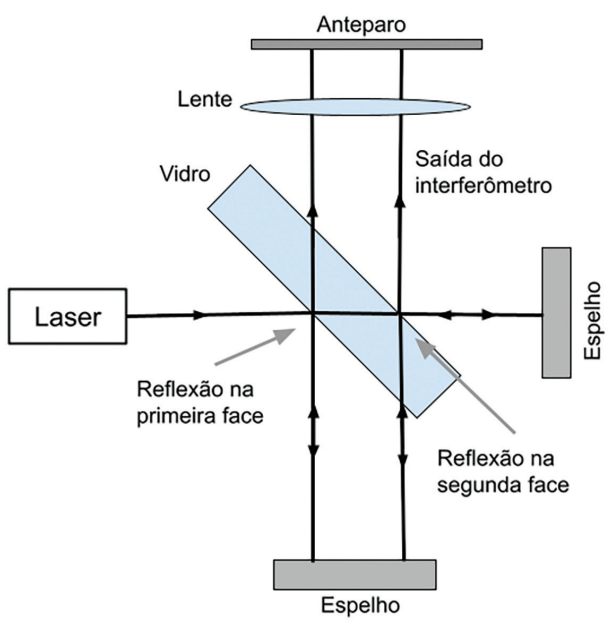

Figura 11: Esquema de um interferômetro de Michelson montado com um divisor de espelho espesso. Reflexões nas duas faces produzem duas saídas distintas.

o semestre de ERE 2020.1, um novo vídeo foi produzido mostrando a montagem completa de um interferômetro de Michelson com materiais de baixo custo, montado na casa do professor regente 4 devido ao caráter de trabalho remoto.

Apesar do grau de dificuldade, a maioria dos alunos (36 em um total de 47 alunos) das turmas de 2018 e 2020, ERE ou EAD, conseguiu montar e observar um padrão de interferência; 7 montaram o interferômetro, mas não conseguiram observar um padrão de interferência e 4 não fizeram o experimento. Dos 7 que não conseguiram completar o experimento, 3 não souberam utilizar a lente para aumentar o diâmetro do feixe de saída do interferômetro. Os demais tiveram problema com o alinhamento dos elementos ópticos do interferômetro. É preciso ressaltar que, em todos estes 7 casos, os alunos não procuraram ajuda do professor ao longo das duas semanas de trabalho, nem por meio de mensagens e nem compareceram nos plantões de dúvidas por webconferência.

A Figura 12 mostra interferômetros montados pelos alunos Marcos, da turma de 2018.1 EAD, e Ricardo, da turma ERE de 2020.1. Ressalta-se que a turma de 2018 não estava em isolamento social, tendo acesso maior a materiais para a montagem do experimento e também apoio do polo do curso EAD. Este fato é visível nas montagens das Figuras 12(a) e (b). Na Figura 12(a) observamos a montagem de Marcos (EAD 2018). Nesta montagem, ele utilizou pedaços de espelhos e vidro conseguidos em uma vidraria. A lente utilizada foi emprestada do Polo. Esses elementos foram anexados em blocos de madeiras, que continham parafusos em sua base que possibilitavam um ajuste fino na inclinação do bloco. Por outro lado, como mostrado na Figura 12(b), o aluno Ricardo (ERE 2020) adaptou materiais que tinha

\footnotetext{
${ }^{4}$ O segundo vídeo está disponível apenas aos alunos da disciplina para manter a privacidade do professor.
}

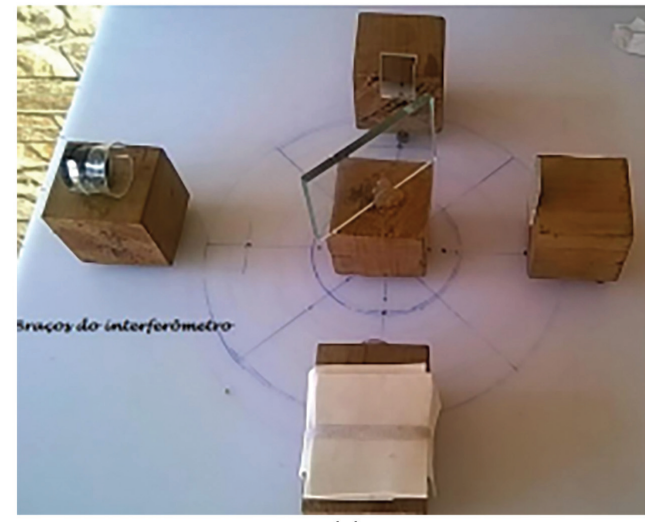

(a)

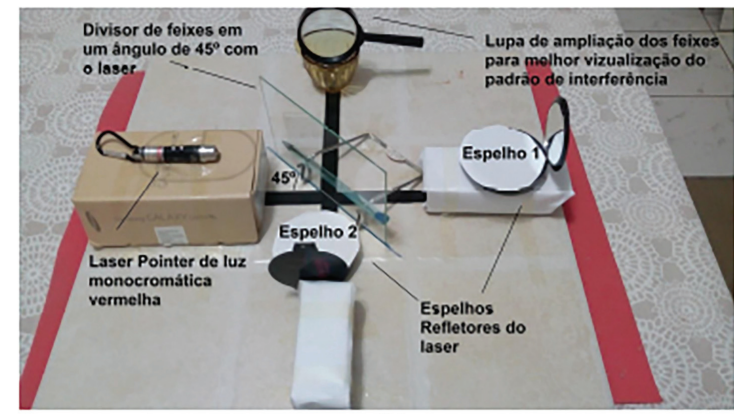

(b)

Figura 12: Interferômetros de Michelson montados pelos alunos: (a) Marcos, da turma EAD 2018.1; (b) Ricardo, da turma ERE 2020.1

em casa, usando, por exemplo, espelhos de estojos de maquiagem cujos ângulos eram ajustados, de maneira grosseira, manualmente.

Na Figura 13 temos 3 exemplos de padrões de interferência apresentados pelos alunos em seus relatórios. Podemos observar nesses padrões os seguintes aspectos: em primeiro lugar, que cada aluno observou franjas de tamanho, orientação e nitidez diferentes. O padrão de interferência visualizado em qualquer interferômetro (inclusive naqueles montados em laboratórios de pesquisa) depende, principalmente, da qualidade dos lasers e também do alinhamento, da limpeza e da qualidade dos elementos ópticos. No caso dos interferômetros feitos pelos alunos, um grande fator para a nitidez do padrão observado é a caneta laser utilizada. A caneta laser verde costuma ser de melhor qualidade em relação à caneta laser vermelha, pela potência emitida, comprimento de coerência e formato do feixe. Entretanto, apesar desta diferença de qualidade, é possível utilizar qualquer um dos dois tipos de laser na realização deste experimento. Observamos, também, na Figura 13 especificamente em (b) e (c), a saída dupla do interferômetro devido ao uso de um divisor de feixe espesso.

\subsection{Espectroscopia}

Outro experimento de montagem muito simples, mas com grande potencial para o estudo de fenômenos físicos 

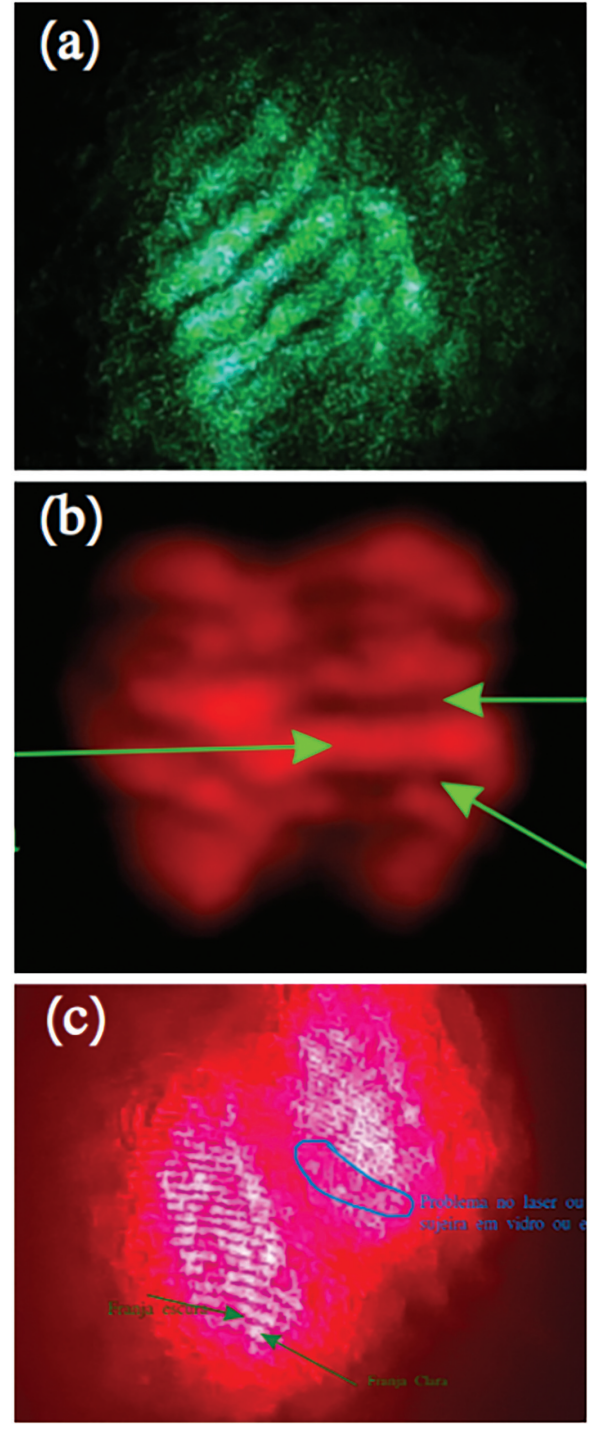

Figura 13: Padrões de interferência obtidos por três alunos da disciplina no experimento do interferômetro de Michelson. Observa-se um padrão mais nítido na Figura (a), feito com a caneta laser verde. Nos padrões (b) e (c) os alunos nitidamente utilizaram um divisor de feixe espesso. Os padrões (a) e (b) foram obtidos pelos alunos Marcos e Ricardo, cujos interferômetros são mostrados na Figura 12 (a) e (b), respectivamente.

é o de espectroscopia. Este experimento foi inspirado na dissertação de Mestrado Profissional em Ensino de Física de T. A. Ricardo [8]. Na adaptação feita para a disciplina de Laboratório de Física IV, os alunos construíram o seu próprio espectrômetro para estudar a relação entre o espectro de fontes luminosas e o fenômeno responsável pela emissão de luz.

O espectrômetro construído utiliza um CD como rede de difração, montado em um suporte de papelão, mostrado na Figura 14 Existem vários vídeos e textos na internet que ensinam como construir este espectrômetro, que pode ser acoplado a um celular para gerar fotografias do espectro da luz espalhada pela rede de difração [8]. Utilizando-se aplicativos de celular ou programas

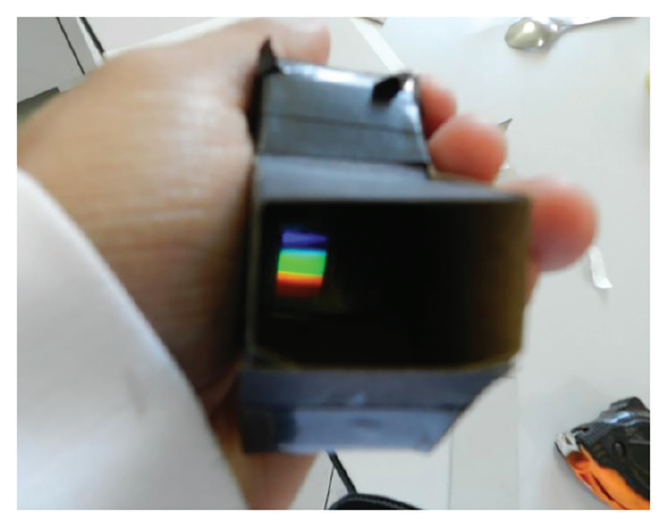

Figura 14: Espectrômetro montado pelo aluno Vagner em 2018.1

específicos, é possível transformar a fotografia do espectro em um gráfico de intensidade por comprimento de onda. Neste trabalho, os alunos foram orientados a utilizar a plataforma Spectral Workbench ${ }^{5}$ que é mantida pela organização não governamental Public Lab. Esta é uma plataforma de acesso livre que possui um banco colaborativo de espectros das mais variadas fontes de luz, textos sobre espectrometria, e tutoriais sobre como montar um espectrômetro de baixo custo e utilizar a plataforma Spectral Workbenc. Além disso, possui uma interface que permite transformar as fotografias de espectros em gráficos de intensidade por comprimento de onda.

Na disciplina de Laboratório de Física IV, os alunos foram instruídos a construir um espectrômetro conforme as referências [8] e [14] e tirar fotografias do espectro de pelo menos 4 fontes de luz entre um conjunto de 8 fontes recomendadas (sol, lâmpada incandescente, lâmpada fluorescente, lâmpada LED, chama do fogão, chama de uma vela, chama de uma vela com sal salpicado, outra fonte de luz de livre escolha).

$\mathrm{Na}$ sequência os alunos utilizaram a plataforma Spectral Workbenck para transformar três fotografias produzidas na primeira etapa em gráficos quantitativos, sendo o espectro do sol e o da lâmpada fluorescente obrigatórios.

Para o relatório, os alunos foram orientados a comparar o gráfico da lâmpada fluorescente com o espectro medido a partir de espectrômetros comerciais fornecidos pelo professor e discutir as limitações de resolução do espectrômetro montado. A partir das fotografias e dos espectros obtidos, eles também precisaram discutir no relatório qual o mecanismo responsável pela emissão de cada um dos 4 espectros fotografados na primeira parte, utilizando os conceitos de física moderna que estavam sendo estudados, em paralelo, na disciplina teórica de Física IV (radiação de corpo negro, emissão por meio de transições de elétrons em níveis de energia de átomos, transições eletrônicas entre bandas de energia em material semicondutor, etc.)

5 Acesso por: https://spectralworkbench.org/ 


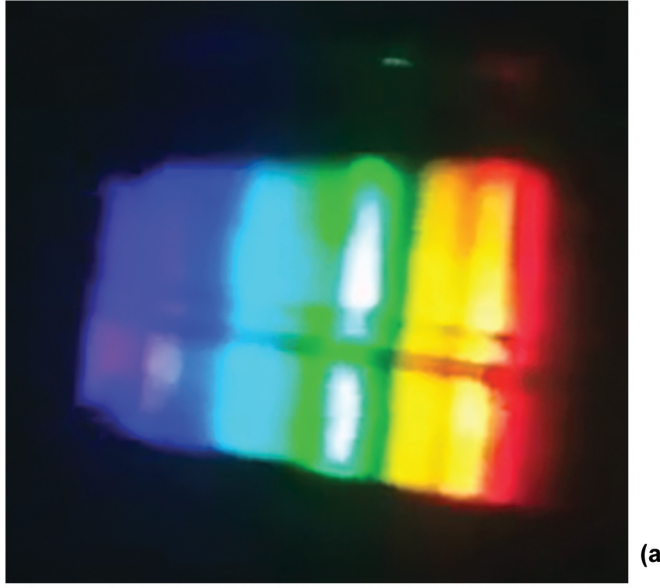

(a)

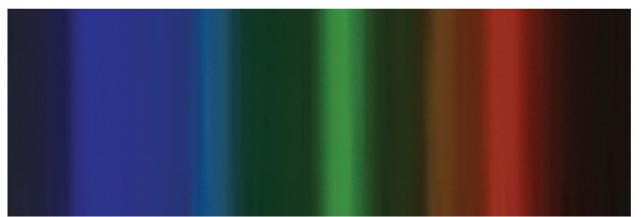

(b)

Figura 15: Fotografias do espectro de lâmpadas fluorescentes. (a) com saturação e problema de foco (Fonte: próprio autor). (b) sem problemas de saturação e foco (Fonte: https://spectralworkbench.org/)

A montagem do espectrômetro foi realizada em todas as turmas aqui estudadas. Nas turmas de EAD 2018 não foi realizada a conversão das fotografias em gráficos. O uso da plataforma Spectral Workbench só foi inserida no experimento a partir de 2020. Em todos os casos, a montagem do espectrômetro foi bem sucedida. Entretanto, foram necessárias orientações adicionais para ajuste das câmeras fotográficas, principalmente nos casos em que as fotografias foram utilizadas para a geração dos gráficos através da plataforma Workbench. Para evitar a saturação da câmera do celular, os alunos foram orientados a colocar o ajuste de sensibilidade da câmera no modo manual, tirar a foto com a câmera pelo menos 1 $m$ de distância do espectrômetro e ajustar a resolução da câmera para o máximo possível. A cada fotografia, devese verificar se nenhuma parte da cor ficou esbranquiçada (sinal de saturação). A Figura 15 mostra duas fotografias do espectro de lâmpadas fluorescentes. Na fotografia (a) observamos que as linhas estão fora de foco e, na linha verde, uma mancha branca indicando a saturação. Na Figura (b), temos um exemplo de espectro sem a saturação e sem problema de foco, para comparação.

A Figura 16 mostra, em (a), a fotografia e o gráfico obtidos do espectro de uma lâmpada fluorescente produzidos pelo aluno Vitor através da plataforma Spectral Workbench e, em (b), o espectro de uma lâmpada fluorescente medido por um espectrômetro comercial de uso científico. A localização dos picos dos gráficos depende dos componentes do pó fluorescente que circunda o vidro das lâmpadas. Por isso, não foi solicitado aos alunos que comparassem a localização ou a intensidade dos

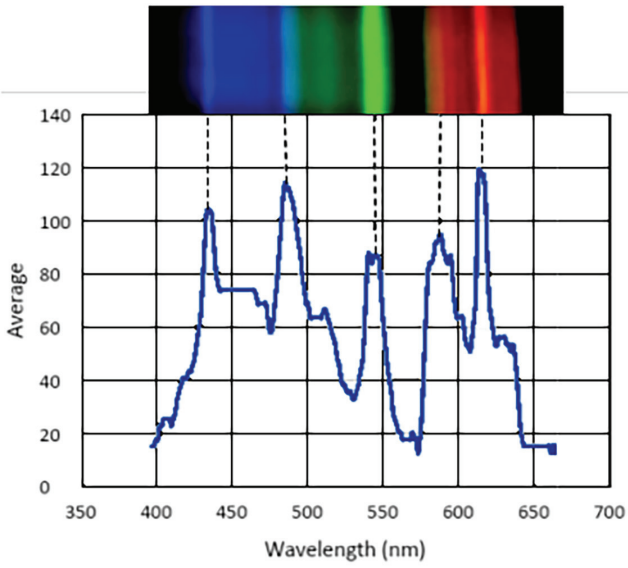

(a)

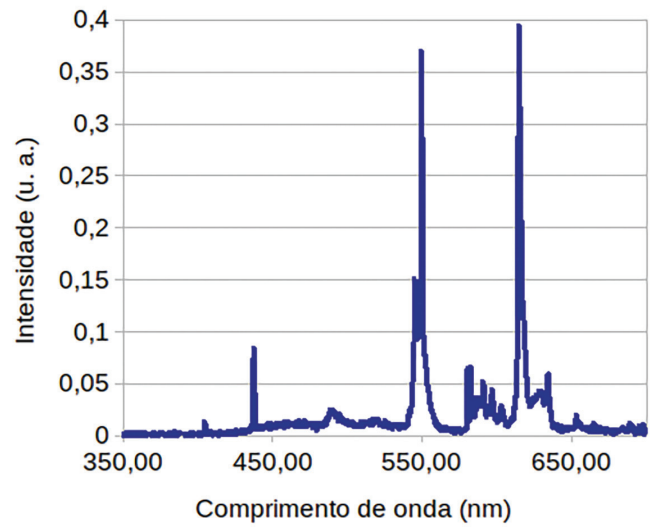

(b)

Figura 16: Gráfico e espectro de uma lâmpada fluorescente produzidos (a) pelo aluno Victor e (b) por um espectrômetro comercial pertencente ao Polo UFJF/IF Sudeste MG do Programa de Mestrado Nacional Profissional em Ensino de Física. Os dois gráficos correspondem a duas lâmpadas fluorescentes diferentes.

picos, mas sim o poder de resolução do espectrômetro de baixo custo comparado com o espectrômetro comercial, ou seja, a largura dos picos. Também foi solicitado que os alunos analisassem o espectrômetro construído e identificassem os elementos que limitam a resolução do gráfico obtido.

\subsection{Relato dos alunos em 2020, sobre a disciplina de 2018.1}

Para analisar a dificuldade na elaboração dos experimentos e do aprendizado obtido, do ponto de vista dos alunos, entramos em contato por e-mail com os alunos do curso de Licenciatura em Física à distância da turma de 2018.1. Neste e-mail, foram solicitadas críticas, sugestões, descrição de dificuldades que tiveram na implementação deste experimento ou qualquer outra informação/opinião que achassem relevantes para a implementação desta disciplina de forma totalmente à distância. Nota-se que, em 2020, no momento em que 
responderam a este e-mail, todos esses alunos já estavam lecionando a disciplina de Física no ensino médio regular. Dos 11 alunos matriculados na época, 5 enviaram suas opiniões.

Todos os 5 alunos que responderam ao nosso e-mail disseram que a abordagem com materiais de baixo custo foi proveitosa e que foi uma solução válida para a continuidade da disciplina devido à greve dos caminhoneiros. Sobre os pontos positivos citados espontaneamente pelos alunos, destacamos os seguintes: 1- os alunos Cláudio e Felipe mencionaram que a disciplina "ofereceu a possibilidade de termos esses experimentos como ferramenta para levarmos para a sala de aula como professores"; 2- aluno Roberto mencionou que os "resultados dos experimentos são mais satisfatórios porque temos mais dedicação para obter um bom resultado"; 3- o aluno Marcos (o mesmo que montou o interferômetro da Figura $12(\mathrm{a})$ ) e o aluno Mauro mencionaram explicitamente que acharam positivo estudar os experimentos a partir de artigos de revistas de ensino e não a partir de roteiros prontos.

Como crítica, o aluno Mauro mencionou a necessidade de os alunos providenciarem os materiais, apesar disso não ter sido um problema para ele. Os alunos Marcos e Cláudio chamaram a atenção para a dificuldade da realização do experimento do interferômetro de Michelson. Entretanto, eles mencionaram que, apesar da dificuldade, a realização do experimento foi proveitosa. O aluno Cláudio, por exemplo, escreveu que realizar este experimento ajudou a “... entender o princípio de funcionamento do aparelho e como a teoria do éter fora refutada, o que ajudou na disciplina de História da Física."

\section{Comentários finais}

Neste trabalho, apresentamos atividades experimentais quantitativas e qualitativas baseadas em materiais de baixo custo e fácil acesso, mostrando que é possível organizar uma disciplina de Laboratório de Física IV de modo emergencial baseada em experimentos realizados pelos alunos em casa.

Nas adaptações dos 5 experimentos para o ensino superior, nos preocupamos em abranger uma variedade de conceitos físicos, abordagens e métodos de análise de dados. Ao longo dos experimentos, cobrimos tópicos de óptica geométrica, óptica física e física moderna. Apresentamos atividades com o intuito de estudar uma Lei Física (Lei de Snell e medida do decaimento da intensidade da luz com a distância), mas também apresentamos experimentos fenomenológicos, como o interferômetro de Michelson e o experimento de espectroscopia. Apresentamos experimentos com roteiros mais estruturados, como a medida da espessura do fio de cabelo, mas também experimentos com um carater mais investigativo, como a atividade de determinação da adequação da luz ambiente ou mesmo o experimento de espectroscopia. Mostramos que é possível criar atividades quantitativas e que envolvem tratamentos de dados trabalhados dentro de disciplinas experimentais de curso superior. Linearização de dados, cálculo e interpretação de médias e desvio padrão, ajuste de curvas não lineares fizeram parte desta abordagem.

Além disso, devido à necessidade de elaboração do experimento como um todo, os alunos passaram por um treinamento usualmente não visto em laboratório presenciais, onde o equipamento é geralmente entregue pronto para os alunos, cabendo a estes apenas a execução da medida. Outro ponto importante que diferencia esta abordagem da tradicional é que todos os alunos elaboraram seus experimentos e seus relatórios. Nas abordagens tradicionais, os alunos normalmente realizam os experimentos e relatórios em grupos, sendo comum alguns alunos trabalharem mais do que outros. Cópias e plágios são minimizados pelo fato dos alunos terem que enviar vídeos e fotografias dos experimentos e porque cada um elabora uma montagem diferente.

A abordagem apresentada aqui é especialmente interessante para os alunos da licenciatura, pois a experiência adquirida e os materiais montados poderão ser utilizados futuramente em atividades de laboratórios em suas próprias aulas. Este fato foi, inclusive, reconhecido por alunos da turma EAD 2018 que atualmente lecionam no ensino médio regular.

Apesar dos alunos EAD já estarem habituados com a rotina de estudar à distância enquanto os alunos presenciais não tinham experiência com ensino não presencial, os resultados obtidos pelos os alunos dos cursos presenciais em caráter ERE foram semelhantes aos alunos EAD, considerando-se frequência na realização dos experimentos, qualidade dos relatórios e busca por ajuda do professor por e-mail, fóruns e mas aulas síncronas. A única diferença observada no desempenho geral dos alunos foi na maior facilidade da aquisição dos materiais pelos alunos da turma EAD 2018, pois eles não estavam em isolamento social e também puderam utilizar a infraestrutura dos polos locais associados ao curso.

Obviamente, a quantidade e o tipo de experimentos realizados em casa é limitado se comparado às possibilidades dos laboratórios presenciais mas, em tempos de pandemia, esta é uma alternativa que cumpre seu papel na formação de alunos, sendo melhor do que atrasar a formatura de alunos ou elaborar uma disciplina de laboratório baseada somente em simuladores e/ou em filmagens de experimentos.

Por outro lado, a abordagem investigava tem vantagens na aprendizagem de Física não apenas para os cursos de licenciatura, mas também para os cursos de bacharelado e engenharias presenciais, uma vez que os alunos são incentivados a participar dos experimentos de maneira ativa e crítica. E, neste sentido, experimentos com materiais de baixo custo e fácil acesso podem complementar atividades de laboratórios presenciais ou EAD no pós-pandemia. Em um primeiro momento de 
transição entre disciplinas ERE e presencial, uma parte da disciplina pode ainda ser realizada em casa. E, mesmo quando a pandemia já estiver controlada, experimentos com materiais de baixo custo ainda têm o potencial de complementar as disciplinas experimentais tradicionais, permitindo a execução de atividades nas quais os alunos são incentivados a elaborar suas próprias metodologias de medidas.

\section{Agradecimentos}

Os autores gostariam de agradecer aos alunos da turma EAD 2018 pelos comentários e críticas enviados, que contribuíram para a adaptação para o formato ERE em 2020, bem como para as discussões deste artigo. Os autores também agradecem aos alunos das turmas ERE em 2020.1, ERE 2020.2, EAD 2018.1 e EAD 2020.2 pela dedicação demonstrada ao longo da disciplina.

\section{Referências}

[1] Greve dos caminhoneiros: a cronologia dos 10 dias que pararam o Brasil, disponível em https://www. bbc.com/portuguese/brasil-44302137, acessado em $12 / 05 / 2018$

[2] S.M. Holz, O.L. Battistel e I.P.S. Sauerwein, Ensino e Pesquisa 18, 136 (2020).

[3] J.C.X. Silva e C.E.S. Leal, Rev. Bras. Ensino Fís. 39, e1401 (2016).

[4] A. Andrade e R.R.P. Teixeira, R. Compartilhar 3, 49 (2019).

[5] A.T. Borges, Cad. Bras. Ens. Fís. 21, 9 (2004).

[6] M.G. Séré, S.M. Coelho e A.D. Nunes, Cad. Bras. Ens. Fís. 20, 30 (2004).

[7] M.S.T. Araújo e M.L.V.S. Abib, Rev. Bras. de Ens. de Fís. 25, 176 (2003).

[8] T.A. Ricardo, Aprendizagem baseada em projetos e feira de ciências: uma associação motivadora para o aprendizado de física moderna. Dissertação de Mestrado, Universidade Federal de Juiz de Fora, 2019.

[9] F. Catelli e S. Vicenzi, Cad. Bras. Ens. Fís. 21, 350 (2004).

[10] C.C. Silva, A.C. Giacomelli, C.A.S. Pérez e B.L. Silva, Rev. Bras. Ens. Ci. Tecnol. 10, 175 (2017).

[11] F.C. Lavarda, Experimentos de Física para Ensino Médio e Fundamental com Materiais do Dia-a-Dia, disponível em: https://www2.fc.unesp.br/experim entosdefisica/, acessado em: 11/05/2021.

[12] R.C. Viscovini, Rev. Bras. Ens. Fís. 22,143 (2000).

[13] É.M. Lopes e C.E. Laburú, Cad. Bras. Ens. Fís. 21, 258 (2004).

[14] L.G. Barros, A. Assis e R. Langhi, Cad. Bras. Ens. Fís. 33, 1026 (2016).

[15] https://youtu.be/zrVvDYiLR5Y, acessado em: $12 / 05 / 2021$.

[16] ABNT - Associação Brasileira de Normas Técnicas, NBR 54113 - Iluminância de interiores (1992), p. 13.

[17] A.C. Feiden, L.T. Konrad, C.S. Rehbein, M.A.R. Edler e M.C. Masutti, Conforto Visual Através da Iluminação
Artificial, em: XXIII Seminário Interinstitucional, XXI Mostra de Iniciação Científica em Ciências Sociais e Humanidades, Trabalho Completo, Unicruz, Cruz Alta, RS (2018), disponível em https://home.unicruz.edu.b r/seminario/anais/anais-2018/XXIIISEMINARIOINT ERINSTITUCIONAL/, acessado em: 12 de maio de 2021.

[18] S.L.A dos Santos, Experimentos de Física Utilizando Materiais de Baixo Custo, $9^{\circ}$ Experimento, disponível em https://experimentos-de-fisica.webnode.com/expe rimentos/optica/, acessado em: 11/05/2021.

[19] A. Medeiros, Física na Escola 14, 57 (2016). 